\title{
Self-mixing interferometry in vertical-cavity surface-emitting lasers for nanomechanical cantilever sensing
}

\author{
Larsson, David; Greve, Anders; Hvam, Jørn Märcher; Boisen, Anja; Yvind, Kresten
}

Published in:

Applied Physics Letters

Link to article, DOI:

$10.1063 / 1.3086893$

Publication date:

2009

Document Version

Publisher's PDF, also known as Version of record

Link back to DTU Orbit

Citation (APA):

Larsson, D., Greve, A., Hvam, J. M., Boisen, A., \& Yvind, K. (2009). Self-mixing interferometry in vertical-cavity surface-emitting lasers for nanomechanical cantilever sensing. Applied Physics Letters, 94(9), 091103. https://doi.org/10.1063/1.3086893

\section{General rights}

Copyright and moral rights for the publications made accessible in the public portal are retained by the authors and/or other copyright owners and it is a condition of accessing publications that users recognise and abide by the legal requirements associated with these rights.

- Users may download and print one copy of any publication from the public portal for the purpose of private study or research.

- You may not further distribute the material or use it for any profit-making activity or commercial gain

- You may freely distribute the URL identifying the publication in the public portal 


\title{
Self-mixing interferometry in vertical-cavity surface-emitting lasers for nanomechanical cantilever sensing
}

\author{
David Larsson, ${ }^{1, a)}$ Anders Greve, ${ }^{2}$ Jørn M. Hvam, ${ }^{1}$ Anja Boisen, ${ }^{2}$ and Kresten Yvind ${ }^{1}$ \\ ${ }^{1}$ Department of Photonics Engineering, Technical University of Denmark, Ørsteds Plads, DK $2800 \mathrm{Kgs}$ \\ Lyngby, Denmark \\ ${ }^{2}$ Department of Micro and Nanotechnology, Technical University of Denmark, Ørsteds Plads, DK 2800 Kgs \\ Lyngby, Denmark
}

(Received 24 November 2008; accepted 28 January 2009; published online 3 March 2009)

\begin{abstract}
We have experimentally investigated self-mixing interference produced by the feedback of light from a polymer micrometer-sized cantilever into a vertical-cavity surface-emitting laser for sensing applications. In particular we have investigated how the visibility of the optical output power and the junction voltage depends on the laser injection current and the distance to the cantilever. The highest power visibility obtained from cantilevers without reflective coatings was $\sim 60 \%$, resulting in a very high sensitivity of $45 \mathrm{mV} / \mathrm{nm}$ with a noise floor below $1.2 \mathrm{mV}$. Different detection schemes are discussed. () 2009 American Institute of Physics. [DOI: 10.1063/1.3086893]
\end{abstract}

Self-mixing interference (SMI) in diode lasers is a wellknown phenomenon and it has been used in various sensing applications such as velocimetry and ranging measurements. ${ }^{1}$ Light is fed back from a reflecting object in an external cavity into the laser cavity, where the condition for threshold gain and phase is altered by the reflected light, thereby changing the threshold, the slope efficiency, the output intensity, and the spectrum. ${ }^{2,3}$ The phase sensitivity is equivalent to conventional optical interferometry with a period of half the laser wavelength, $\lambda_{0} / 2$. The modulation depth is also similar to conventional interferometry. SMI in vertical-cavity surface-emitting lasers (VCSELs) has been investigated by several groups, see, e.g., Refs. 3-6, but few of the publications dealt especially with the sensing application. ${ }^{5,6}$ In this letter we specifically address the application of optical readout for monitoring the deflection of micrometer-sized cantilever sensors.

VCSELs are well suited for SMI as the modulation depth of the intensity variations is enhanced by the low threshold gain, which results in steep gain curves and low threshold photon densities, and by their short cavities. ${ }^{2}$ The reflectivity of the laser mirrors and the number of quantum wells in the gain medium can be tailored to optimize the modulation depth, given a certain external feedback level. The circular symmetric beam with low divergence $\left(\sim 10^{\circ}\right)$ facilitates coupling to distant objects and beam shaping with optics. The surface emission makes it possible to make onedimensional and two-dimensional arrays of VCSELs matching an array of cantilevers, and the two chips can be bonded together, so that no postalignment is necessary.

Micrometer-sized cantilevers are promising candidates for inexpensive, mass-producible, and miniaturized sensors to monitor chemical and biological analytes, e.g., explosives and other illegal substances. Small cantilevers have the advantage of being sensitive to small amounts of analytes. ${ }^{7}$ Polymer cantilevers are less explored than the $\mathrm{Si}$ counterparts but are predicted to offer lower cost and higher sensitivity. ${ }^{8,9}$ Embossing polymers with nanoimprint lithography offers the possibility to structure cantilevers in a wider

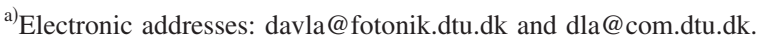

range of polymers, with three-dimensional features, nanosize resolution, and with high volume capacity. Recently, we have imprinted cantilevers in the polymer Topas. ${ }^{10}$ The cantilevers can transduce the induced differential surface stress (from the analyte) into a static deflection, which is usually transduced into an electrical signal by the optical lever method, where a laser beam is reflected off the surface of the cantilever onto a position sensitive detector. ${ }^{7}$ However, the optical lever method is bulky, expensive, and it is not well suited for polymer cantilevers with a low reflectivity. Cantilevers need to be coated with a layer of gold to increase the reflectivity, which introduces unwanted bimorph effects and increases surface complexity. We intend to use SMI in VCSELs where an external cavity is formed between a laser and a cantilever, coated with a thin $(\sim 30 \mathrm{~nm})$ organic film to functionalize it [Fig. 1(a)], and the external cavity length is changed by the deflection of the cantilever caused by the analyte. By leaving the apex of the cantilever uncoated, any induced index change in the functionalizing film will not affect the feedback from the external cavity. Since the semiconductor laser can be monolithically integrated with a photodetector (PD) (Ref. 11), the entire sensing system can be very compact, robust, and simple. There is also the possibility to use the modulation of the laser voltage as a signal, as shown in Fig. 2(a). However, in that case lock-in detection may be needed. ${ }^{6}$

A commercial single-mode $850 \mathrm{~nm}$ top-emitting VCSEL (Advanced Optical Components) is used as the self-mixing nonlinear interferometer. The threshold current of the solitary laser is approximately $0.95 \mathrm{~mA}$, while the slope efficiency is $\sim 0.33 \mathrm{~W} / \mathrm{A}$. The cantilevers, made of Topas $(400 \times 100$ $\times 4.5 \mu^{3}$ ), have been glued to a stage facing the laser diode and the distance was varied by means of a micrometer screw from 35 to $250 \mu \mathrm{m}$, covering the range of expected cantilever anchor thicknesses $(250 \mu \mathrm{m}$ presently) [see Fig. 1(a)]. The signal is obtained by moving the stage with a piezoactuator with $10 \mathrm{~nm}$ minimum step size. The modulated laser light is detected by a PD (Thorlabs PDA100EC) and the voltage variations are read from a digital multimeter. Lateral alignment of cantilever and laser is done by imaging the beam onto a Si charge coupled device camera. To decrease the influence of air flow on the displacement of the cantile- 

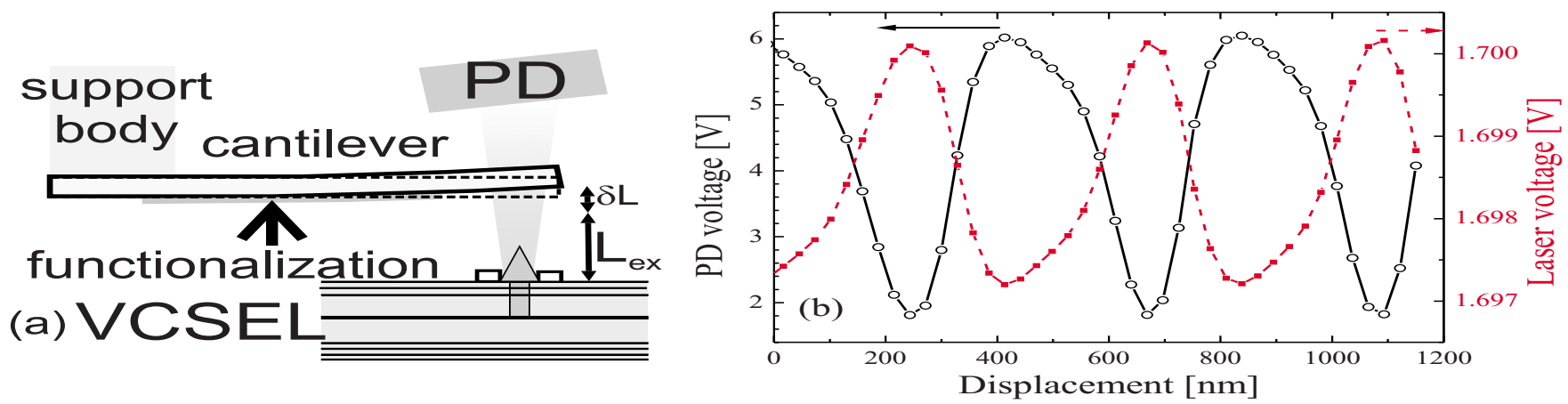

FIG. 1. (Color online) (a) Schematic of measurement setup: PD, Thorlabs PDA100EC amplified PD; $L_{\text {ex }}$, external cavity length; $\delta L$, change in $L_{\text {ex }}$ due to cantilever bending in the final application (here due to piezo's movement). (b) PD voltage and laser voltage signal from Topas cantilever at a distance of $\sim 35 \mu \mathrm{m}$ and a laser current of $0.98 \mathrm{~mA}$.

vers, the setup is shielded by a box of Plexiglas.

In this letter we have investigated a pure displacement by the use of a piezostage since the expected angle of the cantilever's deflection is very low $(<0.24 \mathrm{mrad})$ and thus can be neglected. The lateral displacement of the reflected beam caused by this angle is less than $1 \%$ of the reflected beam waist. Figure 1(b) presents the output signal from the PD versus the piezo's displacement of the cantilever at a distance of $\sim 35 \mu \mathrm{m}$ and a laser drive current of $0.98 \mathrm{~mA}$. The sensitivity can be linearized around the steepest slope and can be as high as $45 \mathrm{mV} / \mathrm{nm}$ in a range of $\pm 25 \mathrm{~nm}$. The standard deviation of the signal from ten consecutive measurements is $\sim 0.25 \%$ [corresponding to $10 \mathrm{mV}$ or $0.2 \mathrm{~nm}$ in Fig. 1(b)]. However, we attribute most of this noise to drift and fluctuations in the piezo and to ambient vibrations. At an amplification of $50 \mathrm{~dB}$ the electrical amplification noise of the detector is $\sim 340 \mu \mathrm{V}(8 \mathrm{pm})$ and the intensity noise from the laser is below $1 \mathrm{mV}$ [calculated from the measured relative intensity noise (RIN) $\left(\mathrm{RIN} \equiv\left\langle\delta P^{2}\right\rangle / P_{\text {ave }}^{2}\right.$, where $\delta P$ is the rms noise value of the optical power, and $P_{\text {ave }}$ is the average optical power) which was below the noise floor of $-128 \mathrm{~dB} / \mathrm{Hz}]$, while the shot noise of the detector is in the range of $100-450 \mu \mathrm{V}(2-10 \mathrm{pm})$ for laser powers of $0.05-1$ $\mathrm{mW}$. The worst case total noise floor of $27 \mathrm{pm}$ can be compared to the thermal noise of the cantilever which is expected to be in the range of $100 \mathrm{pm}$. Up to this date, very few deflection measurements on polymer cantilevers without re- flective coatings have been reported. In Ref. 8 the optical lever technique was used to measure deflections as small as $11 \mathrm{~nm}$, but the maximum resolution was not reported.

It is known that the visibility of the power modulation has a strong dependence on both laser injection current and on the feedback level. Our measurements of the visibility of the power emitted from the top mirror versus the laser current are shown in Fig. 2(a). Three distinct regions can be identified: the peak around the threshold, originating from the changes in threshold current, $I_{\text {th }}$, a dip shortly after, and a constant level. Analytical approximations of the visibility can be found in, e.g., Refs. 1 and 2. However, the authors neglected the periodic changes in the fractional output power given by ${ }^{12}$

$$
F(z)=\frac{T_{\mathrm{eff}}(z)}{\left[1-R_{\mathrm{eff}}(z)\right]+\sqrt{\frac{R_{\mathrm{eff}}(z)}{R_{1}}}\left(1-R_{1}\right)},
$$

where $R_{\text {eff }}$ and $T_{\text {eff }}$ are the effective power reflectivity and transmittivity from the top DBR, while $R_{1}$ is the reflectivity of the bottom DBR of the VCSEL. Because of the small transmittivities of the VCSEL, the small changes in $R_{\text {eff }}$ caused by the feedback lead to large changes in $T_{\text {eff }}$ causing large changes in $F$. Since the VCSEL output is highly nonsymmetric ( $\sim 90 \%$ through top DBR), the relative changes in fractional power are even larger for the bottom DBR. The
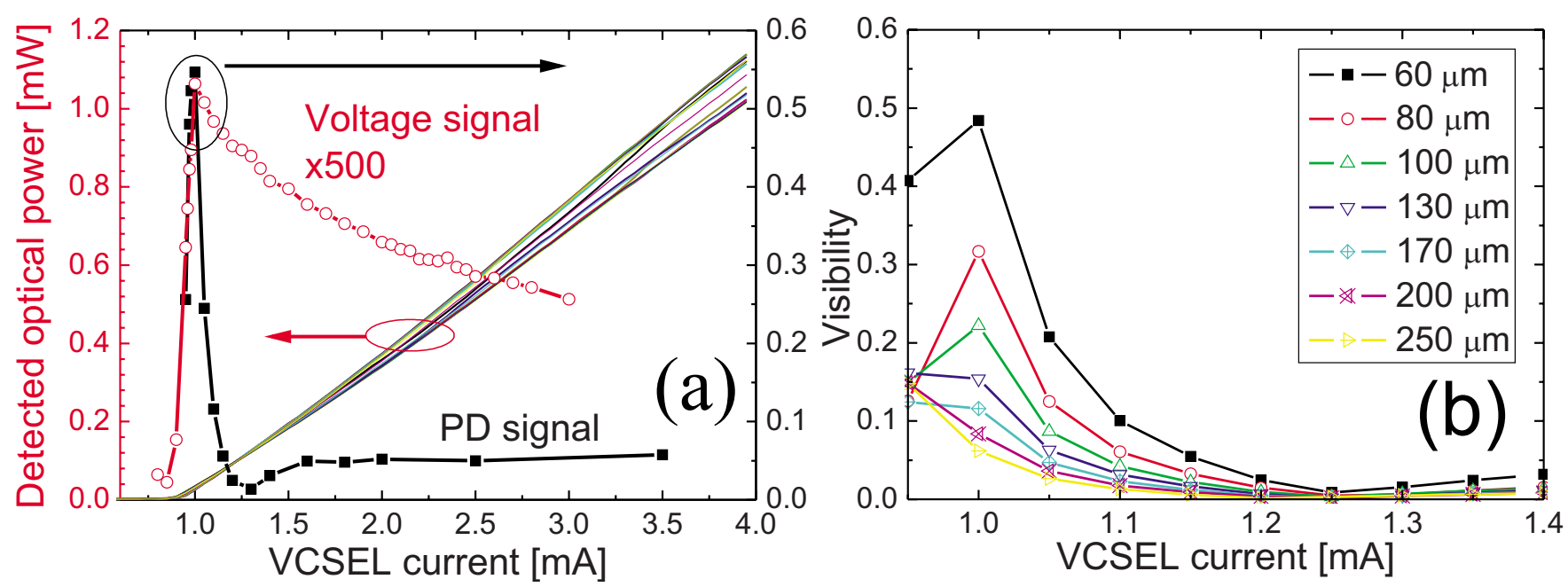

FIG. 2. (Color online) (a) Visibility of PD and laser voltage, and detected power level vs VCSEL current at an external cavity length of $\sim 35 \mu$ m. (b) Visibility of PD vs VCSEL current for different external cavity lengths. 
phase of the changes in $F$ is also important. They are out of phase with the changes in threshold gain on the side facing the feedback, whereas the changes in $F$ on the opposite side are in phase. Thus in general the highest modulation depth can be monitored through the high reflectivity mirror, while the cantilever is placed on the opposite side of the VCSEL. The experimental change in the slope efficiency, $\eta_{d}$, due to the change in fractional output power through the top DBR is as high as $10 \%$ at a feedback distance of $\sim 35 \mu \mathrm{m}$. The out-of-phase side, used in our setup, results in a dip in visibility at approximately

$$
I_{V=0}=\left(\eta_{d}^{\max } I_{\mathrm{th}}^{\mathrm{max}}-\eta_{d}^{\min } I_{\mathrm{th}}^{\min }\right) /\left(\eta_{d}^{\max }-\eta_{d}^{\min }\right),
$$

while the visibility at high currents is only given by the change in differential efficiency

$$
V_{I \rightarrow \infty}=\left|\left(\eta_{d}^{\max }-\eta_{d}^{\min }\right) /\left(\eta_{d}^{\max }+\eta_{d}^{\min }\right)\right| .
$$

Inserting the values from a linear fit of the min and max $L I$ curves in Fig. 2(a), $\eta_{d}=0.35 / 0.39 \mathrm{~W} / \mathrm{A}$ and $I_{\text {th }}$ $=0.98 / 1.01 \mathrm{~mA}$, gives $I_{V=0}=1.26 \mathrm{~mA}$ and $V_{I \rightarrow \infty}=0.05$, which is also measured experimentally. The third detection scheme, to measure the laser voltage visibility, related to the changes in Fermi levels, is also plotted in Fig. 2(a). An attractive feature with this scheme is that the drop in visibility is slower compared to the drop in visibility of the optical power. However, an amplification of $\sim 500$ is needed to get the same amplitude.

The visibility also drops as predicted by theory with decreased feedback level shown in Fig. 2(b) where the feedback drops as the external cavity length increases. To increase the modulation depth and to decrease the influence of variations in laser current, the feedback should be as strong as possible. However, when increasing the feedback level, the intensity noise also increases. This trade-off between visibility and the noise floor has to be further investigated. The best laser current seems to be located at the maximum threshold value during feedback. However, if one would like to use current tuning to tune the feedback phase in order to work on the steepest slope, or if the laser current is to be modulated for resonant sensing, then the flat part of the visibility versus current curve might be the best choice.

This work was funded by the Danish Council for Strategic Research under the NABIIT program.

${ }^{1}$ P. J. de Groot, G. M. Gallatin, and S. H. Macomber, Appl. Opt. 27, 4474 (1988).

${ }^{2}$ W. M. Wang, K. T. V. Grattan, A. W. Palmer, and W. J. O. Boyle, J. Lightwave Technol. 12, 1577 (1994).

${ }^{3}$ A. Hsu, J.-F. P. Seurin, S. L. Chuang, and K. D. Choquette, IEEE J. Quantum Electron. 37, 1643 (2001).

${ }^{4}$ M. A. Arteaga, H. J. Unold, M. Ostermann, R. Michalzik, H. Thienpont, and K. Panatjov, IEEE J. Quantum Electron. 42, 102 (2006).

${ }^{5}$ C. Gorecki, S. Khalfallah, H. Kawakatsu, and Y. Arakawa, Sens. Actuators, A 87, 113 (2001).

${ }^{6}$ D. Heinis, C. Gorecki, S. Bargiel, and B. Cretin, Opt. Express 14, 3396 (2006)

${ }^{7}$ R. Raiteri, M. Grattarola, H.-J. Butt, and P. Skládal, Sens. Actuators B 79, 115 (2001).

${ }^{8}$ M. Calleja, J. Tamayo, M. Nordström, and A. Boisen, Appl. Phys. Lett. 88, 113901 (2006).

${ }^{9}$ J. H. T. Ransley, M. Watari, D. Sukumaran, R. A. McKendry, and A. A. Seshia, Microelectron. Eng. 83, 1621 (2006).

${ }^{10}$ A. Greve, S. Keller, D. Larsson, A. Kristensen, K. Yvind, J. M. Hvam, and A. Boisen (unpublished).

${ }^{11}$ S. Lim, G. Li, W. Yuen, and C. Chang-Hasnain, IEEE J. Sel. Top. Quantum Electron. 3, 416 (1997).

${ }^{12}$ L. Coldren and S. Corzine, Diode Lasers and Photonic Integrated Circuits, 2nd ed. (Wiley, New York, 1995), Chap. 3, p. 78. 